\title{
The metIC operon involved in methionine biosynthesis in Bacillus subtilis is controlled by transcription antitermination
}

\author{
Sandrine Auger, ${ }^{1}$ W. H. Yuen, ${ }^{2}$ Antoine Danchin ${ }^{1} \dagger$ \\ and Isabelle Martin-Verstraete ${ }^{1}$
}
1 Unité de Génétique des Génomes Bactériens, Institut Pasteur, URA CNRS 2171, 28 rue du Docteur Roux, 75724 Paris Cedex 15, France
2 Department of Chemistry, Hong Kong University, Pokfulam Road, Hong Kong

\author{
Author for correspondence: Isabelle Martin-Verstraete. Tel: +33 1456884 41. Fax: +3314568 8948 . \\ e-mail: iverstra@pasteur.fr
}

\begin{abstract}
There are two major pathways for methionine biosynthesis in microorganisms. Little is known about these pathways in Bacillus subtilis. The authors assigned a function to the metl (formerly yjcl) and metC (formerly yjc)) genes of $B$. subtilis by complementing Escherichia coli metB and metC mutants, analysing the phenotype of $B$. subtilis metl and metC mutants, and carrying out enzyme activity assays. These genes encode polypeptides belonging to the cystathionine $\gamma$-synthase family of proteins. Interestingly, the Metl protein has both cystathionine $\gamma$-synthase and 0 -acetylhomoserine thiolyase activities, whereas the MetC protein is a cystathionine $\beta$-lyase. In B. subtilis, the transsulfuration and the thiolation pathways are functional in vivo. Due to its dual activity, the Metl protein participates in both pathways. The metl and metC genes form an operon, the expression of which is subject to sulfurdependent regulation. When the sulfur source is sulfate or cysteine the transcription of this operon is high. Conversely, when the sulfur source is methionine its transcription is low. An S-box sequence, which is located upstream of the metl gene, is involved in the regulation of the met/C operon. Northern blot experiments demonstrated the existence of two transcripts: a small transcript corresponding to the premature transcription termination at the terminator present in the S-box and a large one corresponding to transcription of the complete metIC operon. When methionine levels were limiting, the amount of the full-length transcript increased. These results substantiate a model of regulation by transcription antitermination.
\end{abstract}

Keywords: sulfur metabolism, regulation by antitermination

\section{INTRODUCTION}

The molecular evolution of metabolic pathways is important for investigating the molecular aspects of the origin of life. The large number of newly sequenced genomes should allow us to increase our knowledge of metabolic biodiversity. The biosynthesis of sulfurcontaining amino acids provides an example of pathways which exhibit alternative means for various organisms to synthesize their own metabolites. Indeed, cysteine and homocysteine can be synthesized directly from reduced sulfur, or by the interconversion of these two metabolites (Fig. 1). Homocysteine is then converted into methionine by a methionine synthase.

† Present address: Hong Kong University Pasteur Research Center, Dexter HC Man Building, 8 Sassoon Road, Pokfulam, Hong Kong.
Thiolation pathways directly incorporate sulfide into $O$ acetylserine or $\mathrm{O}$-acetylhomoserine to produce cysteine or homocysteine, respectively. These reactions are catalysed by an O-acetylserine thiolyase (EC 4.2.99.8) (Kredich, 1996), or by an O-acetylhomoserine thiolyase (EC 4.2.99.10) (Yamagata, 1989) (Fig. 1). Saccharomyces cerevisiae (Thomas \& Surdin-Kerjan, 1997) and bacteria such as Brevibacterium flavum (Ozaki \& Shiio, 1982) and Leptospira meyeri (Belfaiza et al., 1998) can synthesize homocysteine by thiolation. The transsulfuration pathways allow the interconversion of homocysteine and cysteine via the intermediary formation of cystathionine (Fig. 1). The synthesis of homocysteine from cysteine is the only means of transsulfuration in enteric bacteria (Greene, 1996). In Escherichia coli this requires the sequential action of cystathionine $\gamma$-synthase (EC 4.2.99.9), the metB gene product (Duchange et al., 


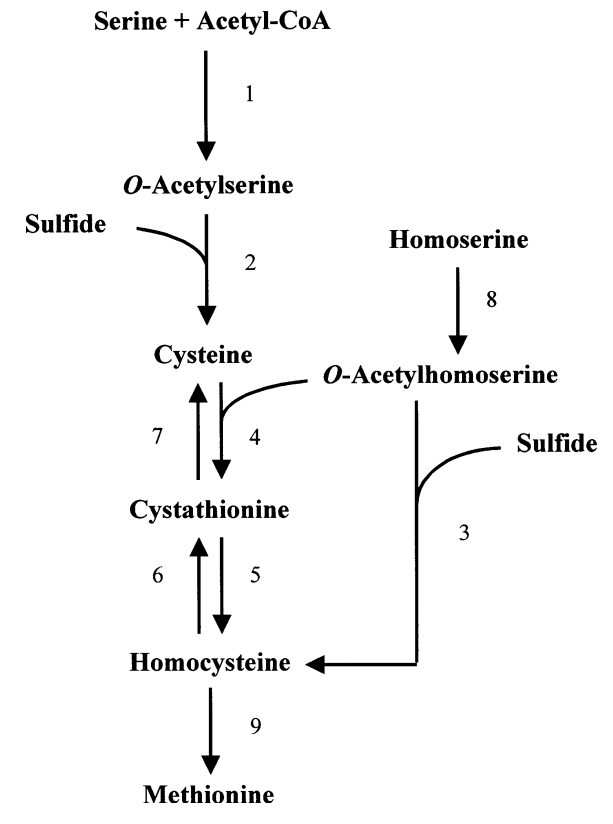

Fig. 1. Biosynthetic pathways of sulfur-containing amino acids. Thiolation pathways: 2, O-acetylserine thiolyase; 3, 0 acetylhomoserine thiolyase. Transsulfuration pathway: 4, cystathionine $\gamma$-synthase; 5 , cystathionine $\beta$-lyase. Reverse transsulfuration pathway: 6 , cystathionine $\beta$-synthase; 7 , cystathionine $\gamma$-lyase. Other steps: 1 , serine transacetylase; 8, homoserine transacetylase; 9, methionine synthase. Most Gram-negative bacteria use $O$-succinylhomoserine instead of $O$-acetylhomoserine.

1983), and cystathionine $\beta$-lyase (EC 4.4.1.8), the met $C$ gene product (Belfaiza et al., 1986). In contrast, mammalian cells only possess the homocysteine to cysteine pathway. This conversion requires a cystathionine $\beta$ synthase (EC 4.2.1.22) and a cystathionine $\gamma$-lyase (EC 4.4.1.1) (Fig. 1). Saccharomyces cerevisiae possesses both of the transsulfuration pathways (Thomas \& Surdin-Kerjan, 1997).

A number of enzymes involved in the metabolism of cysteine, homocysteine and methionine are evolutionarily related (Alexander et al., 1994). Cystathionine $\gamma$ synthase, cystathionine $\beta$-lyase, cystathionine $\gamma$-lyase, $O$-acetylhomoserine thiolyase and methionine $\gamma$-lyase constitute a protein family (Cherest et al., 1993). The number of proteins in this family varies from organism to organism and can reach up to five or six similar polypeptides in Bacillus anthracis, Bacillus halodurans, Clostridium acetobutylicum and Saccharomyces cerevisiae (Thomas \& Surdin-Kerjan, 1997). The existence of paralogues is a recurrent problem in functional genomics. Annotation procedures mostly rely on sequence comparisons. Thus, the functions of newly identified genes are thought to be identical to those of a known reference. However, this method does not address the central question of enzyme recruitment for new activities (Danchin, 1989; Jensen, 1976) and may lead to misleading assignment of functions.

Methionine plays a central role in a variety of cellular functions: it is the universal initiator of protein synthesis and its derivative, $S$-adenosylmethionine, is involved in several cell processes including methylation (Sekowska et al., 2000). Its synthesis is, therefore, tightly regulated. The enzyme producing the homoserine ester is subject to feedback inhibition by methionine and $S$-adenosylmethionine in E. coli and Bacillus subtilis (Brush \& Paulus, 1971; Greene, 1996). The methionine biosynthetic pathway is also regulated at the transcriptional level. Two regulators are involved in this control in $E$. coli: the Met J repressor and the MetR activator (Greene, 1996; Weissbach \& Brot, 1991). The MetJ repressor, interacting with $S$-adenosylmethionine, binds to the Met box sequences and represses the transcription of most of the met genes. MetR stimulates the expression of the metE and met $H$ genes, which encode the methionine synthases. Homocysteine markedly enhances the MetR activation of metE expression.

A number of $B$. subtilis genes and operons that are thought to be involved in methionine or cysteine biosynthesis contain a highly conserved sequence upstream of their coding sequence (Grundy \& Henkin, 1998). This motif, the S-box, includes an element resembling an intrinsic transcriptional terminator, suggesting that regulation is controlled at the level of premature termination of transcription. Grundy \& Henkin (1998) supported a model in which the $5^{\prime}$ portion of the leader forms an anti-antiterminator structure, which sequesters sequences required for the formation of an antiterminator, which, in turn, sequesters sequences required for the formation of the terminator, on the basis of mutational analysis of the leader region of the methionine-regulated yitJ gene. The anti-antiterminator is postulated to be stabilized by the binding of some unknown factor when methionine is available. This set of genes is proposed to form a new regulon, probably controlled by a global transcription termination control system (Grundy \& Henkin, 1998).

We studied the involvement of the yjcI (now metI) and $y j c J$ (now metC) gene products in the biosynthesis of methionine in B. subtilis. We also demonstrated that the $S$-box sequence, which is located upstream of the metI gene, is involved in the regulation of the expression of the metIC operon. This motif modulates the termination of transcription in response to the availability for methionine in the medium.

\section{METHODS}

Bacterial strains and culture conditions. The E. coli and $B$. subtilis strains and plasmids used in this work are listed in Table 1. E. coli cells were grown in L-broth (LB; Sambrook et al., 1989) or in minimal medium M63 (Miller, 1972) containing $1 \mathrm{mM}$ L-methionine if necessary. B. subtilis was grown in SP medium or in minimal medium $\left(6 \mathrm{mM} \mathrm{K}_{2} \mathrm{HPO}_{4}, 4.4 \mathrm{mM}\right.$ $\mathrm{KH}_{2} \mathrm{PO}_{4}, 0.3 \mathrm{mM}$ trisodium citrate, $5 \mathrm{mM} \mathrm{MgCl}_{2}, 0.5 \%$ glucose, $50 \mathrm{mg}$ L-tryptophan $\mathrm{I}^{-1}, 22 \mathrm{mg}$ ferric ammonium citrate $1^{-1}, 0 \cdot 1 \%$ L-glutamine) supplemented with a sulfur source as stated : $1 \mathrm{mM} \mathrm{K}_{2} \mathrm{SO}_{4}, 1 \mathrm{mM} \mathrm{L-methionine,} 1 \mathrm{mM}$ DLhomocysteine, $0.5 \mathrm{mM}$ L-cysteine or $0.1 \mathrm{mM}$ L-cystathionine. Antibiotics were added at the following concentrations when 
Table 1. E. coli and B. subtilis strains used in this study

\begin{tabular}{|c|c|c|}
\hline Strain & Genotype* & Source $†$ \\
\hline \multicolumn{3}{|l|}{ E. coli } \\
\hline WA802 & metB1 lac-3 (or lacY1) galK2 galT22 supE44 hsdR Rif ${ }^{\mathrm{r}}$ & I. Saint-Girons $\ddagger$ \\
\hline CAG18475 & metC162::Tn10 rph-1 & E. coli Genetic Stock Center \\
\hline BL21(DE3) & $\mathrm{F}^{-}$ompT hsd $S_{\mathrm{B}}\left(\mathrm{r}_{\mathrm{B}}^{-} \mathrm{m}_{\mathrm{B}}^{-}\right)$gal dcm (DE3) & Novagen \\
\hline \multicolumn{3}{|l|}{ B. subtilis } \\
\hline 168 & $\operatorname{trpC2}$ & Laboratory stock \\
\hline BSIP1140 & $\operatorname{trp} C 2$ met $C^{\prime}::$ lac $Z$ cat $\Delta m e t C$ & pDIA5509 $\rightarrow 168$ \\
\hline BSIP1142 & $\operatorname{trp} C 2$ amyE: $(\mathrm{pA}$ metI'-lacZ cat) & pDIA5510 $\rightarrow 168$ \\
\hline BSIP1143 & $\operatorname{trpC} 2$ metI : :spc & pDIA5517 $\rightarrow 168$ \\
\hline BSIP1153 & $\operatorname{trp} C 2$ amyE::(pFmetI'-lacZ cat) & pDIA5524 $\rightarrow 168$ \\
\hline BSIP1154 & $\operatorname{trp} C 2$ amyE: : (pCmetI'-lacZ cat) & pDIA5525 $\rightarrow 168$ \\
\hline BSIP1162 & $\operatorname{trp} C 2$ amyE: : (pBmetI'-lacZ cat) & pDIA5540 $\rightarrow 168$ \\
\hline BSIP1163 & $\operatorname{trp} C 2$ amyE::(pEmetI'-lacZ cat) & pDIA5541 $\rightarrow 168$ \\
\hline BSIP1164 & $\operatorname{trp} C 2$ met $C:: s p c$ & pDIA5547 $\rightarrow 168$ \\
\hline BSIP1179 & $\operatorname{trp} C 2$ metI::spc amyE::(pxyl metI cat) & pDIA5544 $\rightarrow$ BSIP1143 \\
\hline BSIP1184 & $\operatorname{trp} C 2$ metI ::spc amyE::(pxyl met $C$ cat $)$ & pDIA5553 $\rightarrow$ BSIP1164 \\
\hline BSIP1229 & $\operatorname{trp} C 2 \Delta($ Sbox-metIC $):: a p h A 3$ & This study \\
\hline BSIP1300 & $\operatorname{trp} C 2$ amyE::(pxylFmetI'-lacZ cat) & pDIA5600 $\rightarrow 168$ \\
\hline BSIP1301 & $\operatorname{trp} C 2$ met $C:: s p c$ amyE: $:(\mathrm{pxyl}$ met $\mathrm{C}$ cat $)$ & pDIA5553 $\rightarrow$ BSIP1164 \\
\hline BSIP1302 & $\operatorname{trp} C 2$ amyE::(pDmetI'-lac $Z$ cat $)$ & pDIA5571 $\rightarrow 168$ \\
\hline
\end{tabular}

* cat, pC194 chloramphenicol acetyltransferase gene; aphA3, Enterococcus faecalis kanamycinresistance gene; $s p c$, spectinomycin-resistance gene.

† Arrows indicate construction by transformation.

‡Unité de Bactériologie Moléculaire et Médicale, Institut Pasteur, Paris, France.

required: $100 \mu \mathrm{g}$ ampicillin $\mathrm{ml}^{-1} ; 10 \mu \mathrm{g}$ tetracycline $\mathrm{ml}^{-1} ; 5 \mu \mathrm{g}$ chloramphenicol ml ${ }^{-1} ; 100 \mu \mathrm{g}$ spectinomycin $\mathrm{ml}^{-1} ; 5 \mu \mathrm{g}$ kanamycin $\mathrm{ml}^{-1}$. Solid media were prepared by addition of $20 \mathrm{~g}$ Agar noble $1^{-1}$ (Difco). Standard procedures were used to transform E. coli (Sambrook et al., 1989) and B. subtilis (Kunst \& Rapoport, 1995). All experiments were performed in accordance with the European regulation requirements concerning the use of genetically modified organisms (GMO level 1 containment, agreement no. 2735).

The loss of amylase activity was detected as described by Stülke et al. (1997). $\beta$-Galactosidase specific activity was measured as described by Miller (1972) with cell extracts obtained by lysozyme treatment. Protein concentrations were determined by the Bradford method (Bradford, 1976). One unit of $\beta$-galactosidase activity was defined as the amount of enzyme that produces $1 \mathrm{nmol} \mathrm{o}$-nitrophenol $\mathrm{min}^{-1}$ at $28^{\circ} \mathrm{C}$. The mean values of at least three independent experiments are presented. Standard deviations (SD) were less than $15 \%$ of the mean.

DNA manipulations. Plasmids from E. coli and chromosomal DNA from B. subtilis were prepared according to standard procedures. Restriction enzymes, Klenow polymerase (Roche), Taq DNA polymerase (Roche) and phage T4 DNA ligase (Biolabs) were used as recommended by the manufacturers. DNA fragments were purified from agarose gels with the Qiaquick kit (Qiagen). DNA sequences were determined using the dideoxy chain-termination method with the Thermo Sequenase kit (Amersham).

Construction of plasmids and strains. To complement the met $B$ and met $C$ mutants of E. coli, the B. subtilis metI (yjcI) and $\operatorname{met} C(y j c J)$ genes were expressed under the control of a lac promoter in pHT315 (Arantès \& Lereclus, 1991). The coding sequences of metI (nucleotides +159 to +1373 relative to the transcription start point) and met $C$ (nucleotides +1197 to +2543 ) were amplified by PCR using primers containing a 5'-BamHI site or a 3'-EcoRI site. These fragments were inserted between the BamHI and EcoRI sites of pHT315.

MetI (nucleotides -55 to +1730 ) and metC (nucleotides +1414 to +2975 ) DNA fragments were amplified by PCR using primers that introduced a BamHI or EcoRI restriction site at the $5^{\prime}$ - or $3^{\prime}$-end. These fragments were inserted into pJH101 (Ferrari et al., 1983), resulting in plasmids pJH101metI and pJH101metC. A SmaI-restricted spectinomycin-resistance cassette (Murphy, 1985) was cloned into the AgeI site of bluntended pJH101metI and into the MluI site of pJH101metC, resulting in pDIA5517 and pDIA5547, respectively. These plasmids, linearized by $S c a$ I, were used to transform B. subtilis 168. The metI or the metC genes were disrupted by the spectinomycin resistance cassette by a double cross-over event, giving rise to strains BSIP1143 and BSIP1164, respectively (Table 1).

Plasmid pX, with its xylose-inducible promoter (Kim et al., 1996), was used to complement B. subtilis metI and metC mutants with the metI and met $C$ genes. The complete coding sequences of metI (nucleotides +159 to +1373 ) and metC (nucleotides +1127 to +2543 ) were amplified by PCR. A SpeI or BamHI restriction site was created at the $5^{\prime}$ - or $3^{\prime}$-end of the fragments. These DNA fragments were inserted into the SpeI and BamHI sites of pX, producing pDIA5544 and pDIA5553. These plasmids were then used to transform different $B$. subtilis mutants, leading to the integration of the metI or metC gene at the amyE locus (Table 1). 
$\longrightarrow \mathrm{A}, \mathrm{B}, \mathrm{C}, \mathrm{D}, \mathrm{E}$

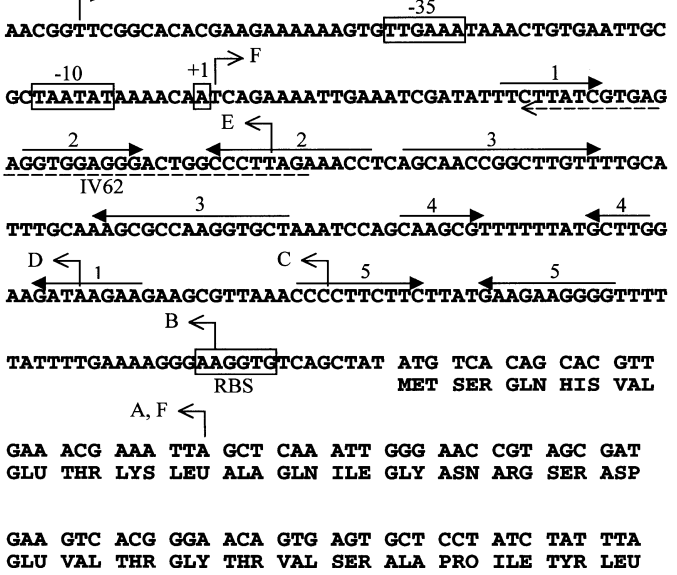

Fig. 2. Nucleotide sequence of the metl upstream region. The -10 and -35 regions, the transcription initiation site $(+1)$ and the putative metl ribosome-binding site (RBS) are indicated. Numbered arrows indicate the positions of inverted repeats corresponding to the helical regions homologous to S-box sequences. The dotted arrow indicates the sequence of the primer used for the primer extension experiment and broken arrows show deletion end-points of the different fusions with the lacZ gene.

A transcriptional met $C^{\prime}-l a c Z$ fusion was constructed as follows : an EcoRI-BamHI internal fragment of the metC gene (nucleotides +1414 to +1730 ), generated by PCR, was cloned into the integrative plasmid pDIA5307 (Calogero et al., 1994). The resulting plasmid, pDIA5509, was integrated by a Campbell-type mechanism into the chromosome of the wildtype strain to create strain BSIP1140.

Plasmid pAC6 (Stülke et al., 1997) allowed the construction of transcriptional fusions between a series of $5^{\prime}$ and $3^{\prime}$ deletions of the metI promoter region and the promoterless lac $Z$ gene. The A (nucleotides -58 to +263 ), B (nucleotides -58 to +198 ), $\mathrm{C}$ (nucleotides -58 to +157 ), $\mathrm{D}$ (nucleotides -58 to +140 ), $\mathrm{E}$ (nucleotides -58 to +55 ) and $\mathrm{F}$ (nucleotides +2 to +263) regions were amplified by PCR, with the creation of EcoRI and BamHI sites. The PCR products were inserted into pAC6 to give pDIA5510 (A), pDIA5540 (B), pDIA5525 (C), pDIA5571 (D), pDIA5541 (E) and pDIA5524 (F), respectively. These plasmids were linearized with $S c a$ I, which allowed the insertion of the transcriptional lac $Z$ fusions as a single copy at the amyE locus (Table 1). Strain BSIP1300 was constructed as follows. A DNA fragment of $3 \mathrm{~kb}$ corresponding to the entire transcriptional fusion $\mathrm{pF}(+2 ;+263)$ metI'-lac $Z$ was amplified by PCR using pDIA5540 as a template. The SpeI-BglII PCR fragment obtained was inserted into the SpeI and BamHI sites of pX (Kim et al., 1996), producing pDIA5600. The transcriptional pxylFmetI'-lacZ fusion was inserted at the amyE locus (Table 1).

To construct strain BSIP1229, in which the S-box and the metIC genes are replaced by a kanamycin-resistance cassette (Trieu-Cuot \& Courvalin, 1983), a four-primer PCR procedure was used (Wach, 1996). The aphA3 gene, encoding the kanamycin-resistance cassette, was first amplified. The regions upstream from the metI gene (nucleotides -1037 to -66 ) and downstream from the metC gene (nucleotides +2254 to +3246) were amplified by PCR so that 21 bp fragments were introduced at one of their ends. Three DNA fragments were then combined: the metI upstream region with a 21 bp aphA3 fragment at its $3^{\prime}$ end, the met $C$ downstream region with a $21 \mathrm{bp} a p h A 3$ fragment at its $5^{\prime}$ end, and the complete aphA3 gene. The metI upstream region and the met $C$ downstream region, overlapping the $a p h A 3$ gene at one end, served as long primers for PCR using $a p h A 3$ as a template. In this second PCR reaction, two external primers $\left(5^{\prime}\right.$ upstream and $3^{\prime}$ downstream primers) were added. The final product, corresponding to the two regions flanking the S-box-metIC sequence with the inserted aphA3 cassette in between, was purified from a gel and used to transform B. subtilis 168 (Table 1).

RNA isolation and analysis. Total RNA was isolated from $B$. subtilis 168 grown in minimal medium supplemented with $1 \mathrm{mM}$ sulfate and/or $1 \mathrm{mM}$ L-methionine. Exponentially growing cells $\left(\mathrm{OD}_{600} 0 \cdot 8\right)$ were harvested. One gram of $0 \cdot 1 \mathrm{~mm}$ diameter glass beads (Sigma) was added. The cells were broken by shaking in a Fastprep apparatus (Bio101) for $2 \times 30$ s. Total RNA was extracted as described by Glatron \& Rapoport (1972).

For the primer extension experiment, the primer IV62 (Fig. 2) labelled with T4 polynucleotide kinase in the presence of $\left[\gamma_{-}{ }^{32} \mathrm{P}\right] \mathrm{ATP}$ was hybridized with $10 \mu \mathrm{g}$ RNA. Annealing was performed at $80^{\circ} \mathrm{C}$ to avoid the secondary structure of RNA. The DNA primer was extended by use of reverse transcriptase and the products were analysed as described by Sambrook et al. (1989). The same primer was used to generate a sequence ladder (Sanger et al., 1977).

For Northern blot analysis, $3 \mu \mathrm{g}$ RNA was separated in a $1.5 \%$ denaturing agarose gel containing $2 \%$ formaldehyde, and transferred to Hybond-N + membrane (Amersham). $[\alpha-$ $\left.{ }^{32} \mathrm{P}\right]$ ATP-labelled probes were generated with the Random Primed DNA labelling kit (Roche). Probe 1 consisted of a 197 bp fragment (nucleotides +1 to +198 ) covering the $S$-box sequence. Probe 2 corresponded to a 304 bp fragment (nucleotides +207 to +511 ) of the metI gene (Fig. 3). Northern blots were analysed and quantified with the Image Master 1D software (Amersham).

Overexpression of Metl. The metI gene (nucleotides +210 to $+1340)$, amplified by PCR using primers introducing a $5^{\prime}$ $\mathrm{NdeI}$ and a $3^{\prime}-\mathrm{XhoI}$ site, was cloned into the pET20b ${ }^{+}$vector (Novagen) which had been digested by NdeI and XhoI. The resulting plasmid, pET20 ${ }^{+}$metl, was transformed into E. coli WA802 (metB1), which carries the T7 RNA polymerase gene on pGP1-2 (Tabor \& Richardson, 1985). Cells were grown at $30{ }^{\circ} \mathrm{C}$ in $\mathrm{LB}$ and transferred to $37^{\circ} \mathrm{C}$ for $2 \mathrm{~h}$ to induce the expression of the metI gene. The pET $20 \mathrm{~b}^{+}$metI construct was also introduced into E. coli BL21(DE3) (Novagen), which contains pDIA17 (Munier et al., 1991) encoding the lacI repressor. Transformants were grown in $\mathrm{LB}$ to $\mathrm{OD}_{600} 3$. The expression of metI was induced by adding IPTG $(3 \mathrm{mM})$. The transformants were incubated for a further $2 \mathrm{~h}$.

Enzyme assays. Cystathionine $\gamma$-synthase catalyses the $\gamma$ replacement reaction with the acetyl ester of L-homoserine and L-cysteine. The reaction mixture contained $100 \mathrm{mM}$ Tris/ $\mathrm{HCl}(\mathrm{pH} 7 \cdot 6), 0.25 \mathrm{mM}$ pyridoxal phosphate, $2.5 \mathrm{mM} \mathrm{O}$ acetyl-L-homoserine, $1 \mathrm{mM}$ L-cysteine and crude cellular extract, and was incubated at $30{ }^{\circ} \mathrm{C}$. The reaction was stopped by incubating at $100^{\circ} \mathrm{C}$ for $2 \mathrm{~min}$. The disappearance of $\mathrm{L}-$ cysteine was measured by the 5,5'-dithiobis-(2-nitrobenzoic acid) (DTNB) method (Jocelyn, 1987). O-Acetylhomoserine thiolyase activity was assayed by measuring how much Lhomocysteine was formed from O-acetyl-L-homoserine and sodium sulfide. The assay was carried out as described above, 
(a)

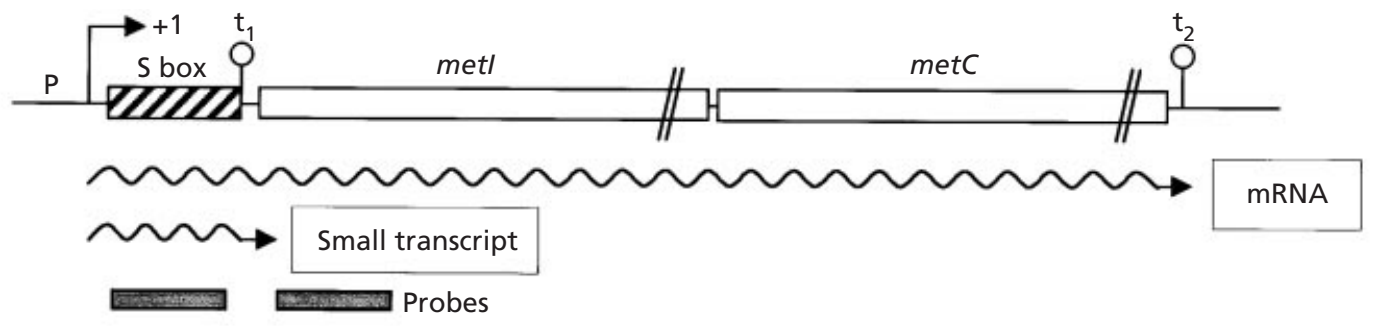

(b)

b)

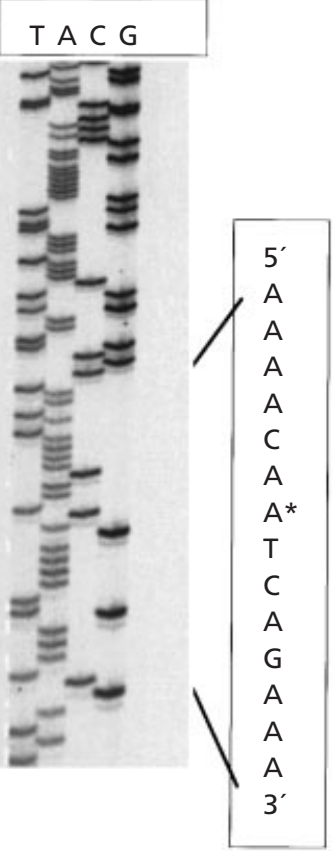

(c)
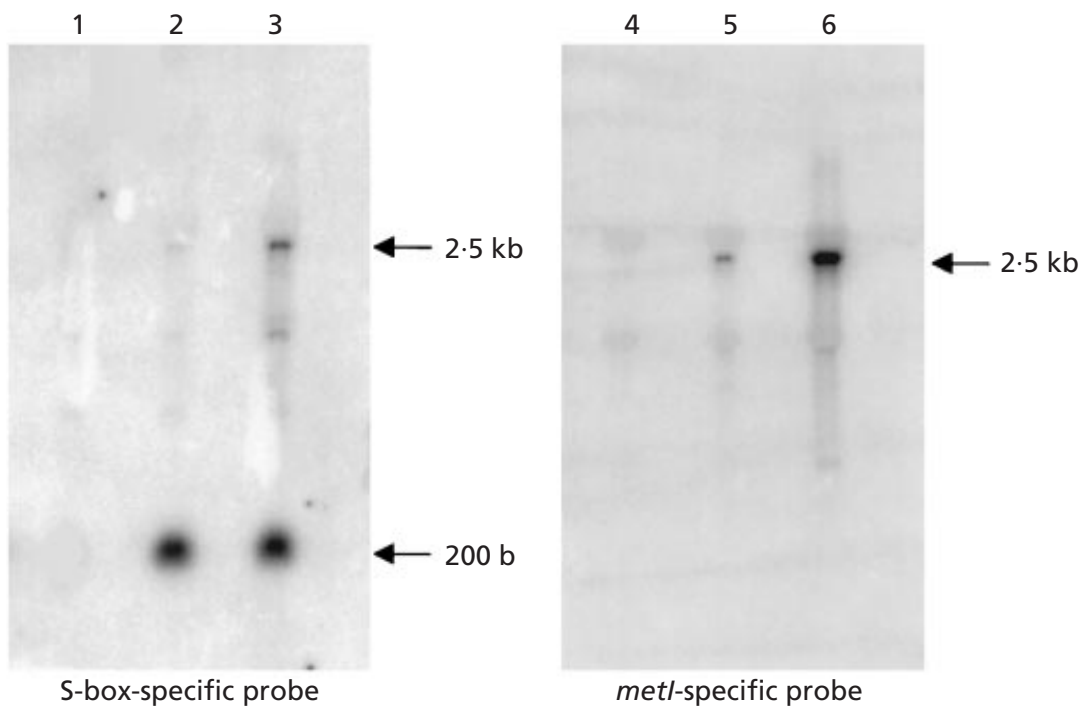

Fig. 3. Genetic organization and transcriptional regulation of the $B$. subtilis met/C operon. (a) Structure of the met/C operon. The promoter $(P)$, the S-box and the transcriptional terminators $\left(t_{1}\right.$ and $\left.t_{2}\right)$ are indicated. The two transcripts of the met/C operon and the DNA fragments used as probes in the Northern blot experiments are also shown. (b) Identification of the transcription start site of the met/C operon by primer extension. Total RNA was extracted from $B$. subtilis 168 grown in minimal medium with $1 \mathrm{mM}$ sulfate as the sole sulfur source. The size of the extended product was compared to a DNA sequencing ladder of the met/C promoter region. The +1 site is marked by an asterisk. (c) Northern blot analysis of the met/C operon. B. subtilis 168 was grown in minimal medium with $1 \mathrm{mM}$ sulfate (lanes 3 and 6) or with $1 \mathrm{mM}$ sulfate and $1 \mathrm{mM}$ methionine (lanes 2 and 5 ) as sulfur sources. The $\Delta$ (S-box-met/C) mutant, BSIP1229, was grown in minimal medium with $1 \mathrm{mM}$ methionine (lanes 1 and 4). Lanes 1, 2 and 3 correspond to hybridization with an S-boxspecific probe. Lanes 4, 5 and 6 correspond to hybridization with a met/-specific probe. Arrows indicate the apparent sizes of the transcripts detected.

except that cysteine was replaced with $8 \mathrm{mM} \mathrm{Na}_{2} \mathrm{~S}$. The amount of L-homocysteine formed was determined by the nitroprusside reaction (Yamagata, 1987). Cystathionine $\beta$ lyase catalyses the conversion of L-cystathionine to ammonia, pyruvate and L-homocysteine. Its activity was assayed at $30{ }^{\circ} \mathrm{C}$ by measurement of the production of free thiol groups with DTNB (Uren, 1987). The reaction mixture contained $100 \mathrm{mM}$ Tris/ $\mathrm{HCl}(\mathrm{pH} 9 \cdot 0$ ), $0 \cdot 2 \mathrm{mM}$ DTNB, $0 \cdot 2 \mathrm{mM}$ pyridoxal phosphate, $2 \mathrm{mM}$ substrate and crude cellular extract.

\section{RESULTS}

\section{Yjcl and YjcJ polypeptides belong to a pyridoxal- dependent enzyme family}

Cystathionine $\gamma$-synthase, cystathionine $\beta$-lyase, cystathionine $\gamma$-lyase and $\mathrm{O}$-acetylhomoserine thiolyase be- long to the same protein family (Cherest et al., 1993). These enzymes, of about 400 aa, use the same cofactor, pyridoxal phosphate, which is attached to a lysine residue (Martel et al., 1987). The sequence surrounding this residue is highly conserved and can be used as a signature pattern to detect this class of enzymes: [DQ]-[LIVMF]-X ${ }_{3}$-[STAGC]-[STAGCI]-T-K-[FYWQ][LIVMF]-X-G-[HQ]-[SGNH] (http://www.expasy.ch/ prosite). Analysis of the complete $B$. subtilis genome sequence revealed the presence of three genes, yjcI, yjcJ and $y r h B$, encoding proteins with similar signature patterns. YjcI, YjcJ and YrhB are proteins of 373, 390 and 379 aa, respectively. A multiple alignment of these polypeptides with the $E$. coli cystathionine $\gamma$-synthase (MetB) and cystathionine $\beta$-lyase (MetC) enzymes showed that the $y j c I, y j c J$ and $y r h B$ gene products share 
Table 2. Complementation of $E$. coli metB and metC mutants by $B$. subtilis yjcl and yjcJ genes

Precultures were grown in M63 medium with $1 \mathrm{mM}$ sulfate plus $1 \mathrm{mM}$ methionine. Cells were centrifuged and resuspended at $\mathrm{OD}_{600} 0 \cdot 1$ in $\mathrm{M} 63$ medium with $1 \mathrm{mM}$ sulfate or $1 \mathrm{mM}$ sulfate plus $1 \mathrm{mM}$ methionine as sulfur source. $\mathrm{OD}_{600}$ was measured after $12 \mathrm{~h}$ growth at $37^{\circ} \mathrm{C}$.

\begin{tabular}{|lllc|}
\hline \multirow{2}{*}{ E. coli strain (relevant genotype) } & Plasmid & \multicolumn{2}{c|}{ OD $_{\mathbf{6 0 0}}$ after 12 h } \\
\cline { 3 - 4 } & & Sulfate & Sulfate + Methionine \\
\hline \multirow{2}{*}{ WA802 (metB1) } & pHT315 & $0 \cdot 12$ & $4 \cdot 0$ \\
& pHT315 yjcI & $1 \cdot 00$ & $4 \cdot 0$ \\
CAG18475 (metC162:: Tn10) & pHT315 yjcJ & $0 \cdot 14$ & $4 \cdot 5$ \\
& pHT315 & $0 \cdot 20$ & $1 \cdot 8$ \\
& pHT315 yjcl & $0 \cdot 09$ & $2 \cdot 0$ \\
& pHT315 yjcJ & $2 \cdot 20$ & $2 \cdot 2$ \\
\hline
\end{tabular}

Table 3. Phenotype of the $B$. subtilis yjcl and yjcJ mutants

Cells were grown in minimal medium containing the various sulfur sources indicated. For expression of the genes under the control of the $x y l$ A promoter, minimal medium contained fructose instead of glucose and $0 \cdot 1 \%$ xylose. NG, No growth; ND, not determined.

\begin{tabular}{|c|c|c|c|c|c|c|}
\hline \multirow[t]{2}{*}{ Strain } & \multirow[t]{2}{*}{ Relevant genotype } & \multicolumn{5}{|c|}{ Doubling time (min) } \\
\hline & & $\begin{array}{l}\text { Sulfate } \\
(1 \mathrm{mM})\end{array}$ & $\begin{array}{l}\text { Cysteine } \\
(0.5 \mathrm{mM})\end{array}$ & $\begin{array}{c}\text { Cystathionine } \\
(0 \cdot 1 \mathrm{mM})\end{array}$ & $\begin{array}{l}\text { Homocysteine } \\
\qquad(1 \mathrm{mM})\end{array}$ & $\begin{array}{l}\text { Methionine } \\
\quad(1 \mathrm{mM})\end{array}$ \\
\hline 168 & & 48 & 57 & 50 & 53 & 55 \\
\hline BSIP1143 & $y j c I:: s p c$ & NG & NG & NG & 63 & 55 \\
\hline BSIP1179 & $y j c I:: s p c$ amyE::pxylyjcI & 56 & ND & NG & ND & ND \\
\hline BSIP1184 & $y j c I:: s p c$ amyE::pxylyjcJ & NG & ND & 105 & ND & ND \\
\hline BSIP1164 & $y j c J:: s p c$ & 55 & 57 & NG & 63 & 54 \\
\hline BSIP1301 & $y j c J:: s p c$ amyE::pxylyjcJ & 58 & ND & 60 & ND & ND \\
\hline
\end{tabular}

$38-42 \%$ identity with MetB, and $27-30 \%$ identity with MetC. The yjcl and yjcJ genes are adjacent on the chromosome. The nucleotide sequence of yjcI overlaps that of $y j c J$ at the sequence TTGA, where TTG is the initiation codon of yjcJ and TGA is the stop codon of $y j c l$. This strongly suggests that these two genes form an operon.

\section{Complementation of $E$. coli metB and metC mutants with $B$. subtilis $y j c l$ and $y j c J$ genes}

E. coli met $B$ and met $C$ mutants lacking cystathionine $\gamma$ synthase or cystathionine $\beta$-lyase activity, respectively, are methionine auxotrophs (Greene, 1996). To determine the function of the B. subtilis yjcI and yjcJ genes, we first tried to complement E. coli metB and metC mutants. The yjcI and yjcJ genes were cloned into the replicative vector pHT315, under the control of the lac promoter. The plasmids pHT315, pHT315yjcl and pHT315yjcJ were introduced into the E. coli mutants WA802 (metB1) and CAG18475 (metC162::Tn10) (Table 1). In a minimal medium with sulfate as sulfur source, pHT315yjcI restored the growth of the metB mutant, whereas pHT315yjcJ allowed the growth of the
metC mutant (Table 2). pHT315 alone did not complement these mutants. In a methionine-supplemented medium, all strains were able to grow. These results strongly suggest that the $\mathrm{YjcI}$ product is a cystathionine $\gamma$-synthase and that the YjcJ product is a cystathionine $\beta$ lyase.

\section{Phenotype of the $y j c l$ and $y j c J$ B. subtilis mutant strains}

To investigate the physiological role of the $y j c I$ and $y j c J$ genes in homocysteine biosynthesis, we disrupted their coding region by double-crossover events that resulted in marker replacement. Growth of the wildtype, the BSIP1143 (yjcI::spc) and the BSIP1164 $(y j c J:: s p c)$ strains was compared in minimal medium containing various sulfur sources (Table 3 ). The yjcI mutant was unable to grow in the presence of sulfate, cysteine or cystathionine as sole sulfur source, whereas its growth in the presence of homocysteine or methionine was similar to that of the wild-type strain. In contrast, the mutant lacking yjcJ grew as well as the wild-type in the presence of sulfate, cysteine, homo- 
cysteine or methionine as sole sulfur source. However, this mutant did not grow in the presence of cystathionine.

The absence of growth of the yjcI mutant in the presence of cystathionine may be due to a polar effect on the yjcJ gene, which is located downstream of $y j c l$ on the $B$. subtilis chromosome. To test this hypothesis, the yjcI or the $y j c J$ genes, expressed under the control of the $x y l A$ promoter, were integrated as a single copy at the amyE locus of the BSIP1143 (yjcI::spc) and BSIP1164 $(y j c J:: s p c)$ mutants (Table 1). The introduction of the yjcJ gene in trans restored the growth of both the yjcJ and yjcl mutants in the presence of cystathionine. The $y j c I$ gene in trans allowed the yjcI mutant to grow in the presence of sulfate, but not in the presence of cystathionine (Table 3). Thus, the lack of growth of the yjcI mutant with cystathionine was a consequence of a polar effect on the expression of the $y j c J$ gene.

The E. coli metB mutant and the B. subtilis yjcI mutant are not able to grow on sulfate or cysteine. Unexpectedly, the B. subtilis yjcJ mutant was not auxotrophic for methionine, in contrast to the E. coli metC mutant. The fact that the YjcJ protein was not essential for homocysteine biosynthesis when sulfate was the sole sulfur source indicated that some other pathway must ensure the conversion of $\mathrm{O}$-acetylhomoserine to homocysteine in $B$. subtilis. We hypothesized that the product of the $y r h B$ gene, which shares $52 \%$ identity with YjcJ, was involved in this pathway. To test this possibility, a double yjcJ yrhB mutant was constructed. In media containing sulfate, this strain showed the same growth rate as the $y j c J$ mutant, indicating that the YrhB polypeptide was not necessary for homocysteine biosynthesis (data not shown). Another hypothesis was that the YjcI polypeptide has both cystathionine $\gamma$-synthase and $O$-acetylhomoserine thiolyase activities. Therefore, the enzyme activity of the YjcI and YjcJ polypeptides was tested.

\section{YjcJ, an enzyme with cystathionine $\beta$-lyase activity, and Yjcl, an enzyme with both cystathionine $\gamma$ - synthase and $\boldsymbol{O}$-acetylhomoserine thiolyase activities}

To avoid cystathionine $\beta$-lyase activity due to MetC, E. coli CAG18475(metC162::Tn10) was used to overproduce the $\mathrm{YjcJ}$ polypeptide. Cystathionine $\beta$-lyase activity, using cystathionine as substrate, was observed in crude extracts of cells transformed with pHT315yjcJ $\left.\left[16.2 \mu \mathrm{mol} \text { free thiol groups } \min ^{-1} \text { (mg protein }\right)^{-1}\right]$. Enzyme activity was also observed with DL-djenkolic acid $\left[18 \cdot 8 \mu \mathrm{mol}\right.$ free thiol groups $\left.\min ^{-1}(\mathrm{mg} \text { protein })^{-1}\right]$, cystine $\left[4 \cdot 2 \mu \mathrm{mol}\right.$ free thiol groups $\left.\mathrm{min}^{-1}(\text { mg protein })^{-1}\right]$ and lanthionine $\left(0 \cdot 8 \mu \mathrm{mol}\right.$ free thiol groups $\mathrm{min}^{-1}(\mathrm{mg}$ protein $)^{-1}$. The activities detected in crude extracts of the same strain transformed with pHT315 were lower than $0 \cdot 1 \mu \mathrm{mol}$ free thiol groups $\min ^{-1}(\mathrm{mg} \text { protein })^{-1}$. These results permitted us to conclude that yjcJ encodes a cystathionine $\beta$-lyase. We propose to rename this gene $m e t C$. Consequently, the former met $C$ gene, encoding the probable methionine synthase, was renamed metE according to SubtiList (http://genolist.pasteur.fr/ SubtiList).

Cystathionine $\gamma$-synthase activity of the YjcI polypeptide was assayed in an E. coli metB mutant (WA802). E. coli cells transformed with pET20 ${ }^{+} y j c I$ exhibited cystathionine $\gamma$-synthase activity with $O$-acetylhomoserine as substrate $\left[1.5 \mu \mathrm{mol}\right.$ cysteine $\left.\mathrm{min}^{-1}(\mathrm{mg} \text { protein })^{-1}\right]$. Under the same conditions, no detectable activity $\left.\left[\leqslant 10^{-3} \mu \mathrm{mol} \text { cysteine } \mathrm{min}^{-1} \text { (mg protein }\right)^{-1}\right]$ was obtained using $\mathrm{O}$-succinylhomoserine, or in crude extracts of cells harbouring pET20 $\mathrm{b}^{+}$. O-Acetylhomoserine thiolyase activity of $\mathrm{YjcI}$ was tested in E. coli strain BL21(DE3). Crude extracts of BL21(DE3) transformed with pET20 ${ }^{+} y j c I$ showed $O$-acetylhomoserine thiolyase $\left[7 \mu \mathrm{mol}\right.$ homocysteine $\left.\min ^{-1}(\mathrm{mg} \text { protein })^{-1}\right]$ and $\mathrm{O}$-succinylhomoserine thiolyase $[6.7 \mu \mathrm{mol}$ homocysteine $\min ^{-1}$ (mg protein $)^{-1}$ ] activities. In crude extracts of the same strain transformed with pET20 $\mathrm{b}^{+}$ vector alone, the activities were lower than $0 \cdot 1 \mu \mathrm{mol}$ homocysteine $\min ^{-1}(\mathrm{mg} \text { protein })^{-1}$. The YjcI polypeptide has both cystathionine $\gamma$-synthase and $O$ acetylhomoserine thiolyase activities in vitro.

To investigate whether the YjcI polypeptide can provide $\mathrm{O}$-acetylhomoserine thiolyase activity in vivo, we tested the ability of the YjcI polypeptide to complement a B. subtilis $\Delta y j c I J$ mutant (BSIP1229) by introducing pHT315yjcl into this strain. Growth experiments in liquid minimal medium showed that the yjcI gene restored the growth of the $\Delta y j c I J$ mutant in the presence of sulfate as sole sulfur source. The doubling time (50 min) was similar to that of the wild-type strain in the same conditions. Thus, the $\mathrm{Yjcl}$ enzyme also has $\mathrm{O}$ acetylhomoserine thiolyase activity in vivo which allows it to bypass the intermediate cystathionine to form homocysteine (Fig. 1). The B. subtilis YjcI and the E. coli MetB polypeptides have different functions. We therefore propose to rename yjcI metI rather than metB.

\section{Regulation of the expression of the met/C operon}

To study the regulation of the metI and met $C$ genes in response to sulfur availability, metI'-lacZ and met $C^{\prime}-l a c Z$ transcriptional fusions were constructed. The met $I^{\prime}-$ lac $Z$ fusion was inserted as a single copy at the amyE locus of B. subtilis 168 (strain BSIP1142), and the met $C^{\prime}-$ lac $Z$ fusion was integrated at the homologous $m e t C$ locus by a Campbell-type mechanism (strain BSIP1140), leading to the disruption of this gene. The level of $\beta$-galactosidase activity was high in the presence of sulfate but 11- to 13-fold lower when both sulfate and methionine were present in the medium (Table 4). The presence of cysteine, cystathionine or homocysteine as sulfur sources led to a high level of expression of the two fusions. The regulation of expression of the metI and met $C$ genes occurs at the transcriptional level. The decrease of expression of these genes in the presence of methionine substantiates the role of the MetI and MetC polypeptides in the methionine biosynthetic pathway.

The met I and met $C$ genes, which are adjacent in the $B$. subtilis chromosome, are co-regulated (Table 4). To 
Table 4. Expression of transcriptional pAmetl'-lac $Z$ and $m e t C^{\prime}-l a c Z$ fusions in the presence of different sulfur sources

Cells were grown in minimal medium containing the various sulfur sources indicated. Values are the means from at least three independent experiments. NG, No growth.

\begin{tabular}{|c|c|c|}
\hline \multirow[t]{2}{*}{ Sulfur source } & \multicolumn{2}{|c|}{$\beta$-Galactosidase activity $\left[\mathrm{U}(\mathrm{mg} \text { protein })^{-1}\right]$} \\
\hline & BSIP1142 amyE::pAmetI'-lacZ & BSIP1140 met $C^{\prime}-l a c Z$ \\
\hline Sulfate (1 mM) & 515 & 265 \\
\hline Methionine $(1 \mathrm{mM})$ & 100 & 80 \\
\hline Sulfate $(1 \mathrm{mM})+$ Methionine $(1 \mathrm{mM})$ & 45 & 20 \\
\hline Cystathionine $(0 \cdot 1 \mathrm{mM})$ & 430 & NG \\
\hline Cysteine $(0.5 \mathrm{mM})$ & 475 & 245 \\
\hline Homocysteine (1 mM) & 340 & 330 \\
\hline
\end{tabular}

Table 5. Effect of sulfate and methionine on the expression of different metl'-lacZ transcriptional fusions

Cells were grown in minimal medium containing the indicated sulfur sources at $1 \mathrm{mM}$. Samples were taken during the exponential growth phase at $\mathrm{OD}_{600} \sim 1$. Values are the means from at least three independent experiments.

\begin{tabular}{|c|c|c|c|c|c|}
\hline \multirow[t]{2}{*}{ Strain } & \multirow[t]{2}{*}{ Fusion at the $a m y E$ locus* } & \multicolumn{3}{|c|}{$\beta$-Galactosidase activity $\left[\mathrm{U}(\mathrm{mg} \text { protein })^{-1}\right]$} & \multirow[t]{2}{*}{ Regulation factor $\dagger$} \\
\hline & & Sulfate & Methionine & Sulfate + Methionine & \\
\hline BSIP1142 & $\mathrm{pA}(-58 ;+263)$ metI'-lacZ & 515 & 100 & 45 & 11 \\
\hline BSIP1162 & $\mathrm{pB}(-58 ;+198)$ metI - lacZ & 85 & 8 & 4 & 21 \\
\hline BSIP1154 & $\mathrm{pC}(-58 ;+157)$ metI $I^{\prime}-l a c Z$ & 520 & 530 & 560 & $0 \cdot 9$ \\
\hline BSIP1302 & $\mathrm{pD}(-58 ;+140)$ metI $I^{\prime}-l a c Z$ & 470 & 450 & 550 & $0 \cdot 8$ \\
\hline BSIP1163 & $\mathrm{pE}(-58 ;+55)$ metI $I^{\prime}-l a c Z$ & 390 & 390 & 355 & $1 \cdot 1$ \\
\hline BSIP1153 & $\mathrm{pF}(+2 ;+263)$ metI $I^{\prime}-$ lac $Z$ & $0 \cdot 5$ & 2 & 0.5 & 1 \\
\hline
\end{tabular}

* The DNA fragment of the metI promoter region is indicated and the nucleotides are numbered taking the transcriptional start site as +1 .

$\dagger \beta$-Galactosidase activity ratio sulfate: sulfate + methionine.

confirm the existence of a metIC operon, we carried out Northern blot experiments with total RNA isolated from B. subtilis 168 grown with sulfate as sole sulfur source. Hybridization with a metI-specific probe revealed a single $2.5 \mathrm{~kb}$ transcript, which corresponds to the size of a bicistronic metIC mRNA (Fig. 3c).

\section{Identification of the metl promoter}

The DNA sequence of the metI promoter region is presented in Fig. 2. The translation initiation codon is an ATG preceded by a reasonable ribosome-binding site. The S-box motif is located upstream of the metI translation start site. The $5^{\prime}$-end of the transcript was identified by primer extension using an oligonucleotide complementary to a region near the $5^{\prime}$-end of the S-box (Fig. 2) and total RNA from B. subtilis 168 grown in minimal medium with sulfate as sulfur source. Transcription is initiated at an A residue located $211 \mathrm{bp}$ upstream of the translational start site (Fig. 3b). The deduced -35 (TTGAAA) and -10 (TAATAT) regions of the promoter, boxed in Fig. 2, are similar to the consensus sequence of $\sigma^{\mathrm{A}}$-dependent promoters.

To confirm the position of the promoter, a transcriptional fusion was constructed between the lac $Z$ gene and the metI promoter $\mathrm{F}$ region (nucleotides +2 to +263 relative to the transcription start site) with deletion of the -35 and -10 regions. The fusion was integrated at the amyE locus of $B$. subtilis. Compared to the $\mathrm{pA}(-58 ;+263)$ metI $^{\prime}-$ lac $Z$ fusion, this fusion gave very low $\beta$-galactosidase activities in minimal media in the presence of either methionine or sulfate as sulfur source (Table 5). Therefore, deletion of the mapped promoter abolished transcription of the metI'-lacZ fusion, indicating the existence of a single promoter.

\section{Role of the S-box in the regulation of the expression of the met/C operon}

The cis-acting elements required for the regulation of the metIC operon are present in the $\mathrm{pA}(-58$; +263) metI'-lacZ transcriptional fusion. This region 
contains the metIC promoter and the S-box sequence. To determine the minimal sequence necessary for full regulation of the operon, metI promoter regions containing various $3^{\prime}$ deletions were fused with the promoterless lac $Z$ gene. The fusion end-points are indicated in Fig. 2. These fusions were introduced as a single copy at the amyE locus of B. subtilis 168 .

Expression of the $\mathrm{pB}(-58 ;+198)$ metI'-lacZ fusion, which contains the entire S-box sequence, was 21-fold higher in the presence of sulfate than in the presence of sulfate plus methionine (Table 5$)$. In contrast, $\mathrm{pC}(-58$; +157)metI'-lacZ and $\mathrm{pD}(-58 ;+140)$ metI'-lacZ deletions caused a high $\beta$-galactosidase activity during growth in the presence or absence of methionine. These results indicate that the DNA fragment located between nucleotides +157 and +198 is necessary for the regulation in response to methionine availability. This region contains a putative factor-independent terminator (helix 5, Fig. 2) probably involved in premature transcription termination (Grundy \& Henkin, 1998). The $\mathrm{pE}(-58 ;+55)$ metI $^{\prime}-$ lac $Z$ fusion only contains the promoter and the $5^{\prime}$ end of the S-box (half of helix 1 and half of helix 2). This fusion also exhibited high-level constitutive expression, indicating that the metIC promoter was constitutively active.

To confirm the respective role of the promoter and the $S$ box in the regulation of the metIC operon, we constructed a transcriptional fusion in which the metI promoter was replaced by the $x y l A$ promoter. The resulting construct was integrated at the amyE locus, giving strain BSIP1300. The $\beta$-galactosidase activity was measured after growth in minimal medium with $0.1 \%$ xylose. The level of $\beta$-galactosidase activity was $75 \mathrm{U}$ $(\mathrm{mg} \text { protein })^{-1}$ in the presence of sulfate, $28 \mathrm{U}(\mathrm{mg}$ protein $)^{-1}$ in the presence of methionine, and $10 \mathrm{U}(\mathrm{mg}$ protein $)^{-1}$ in the presence of sulfate and methionine. Although the level of expression was lower than that observed for the native pAmetI $I^{\prime}$ lac $Z$ fusion, the trend was similar. The S-box sequence is, therefore, sufficient to mediate the regulation of the metIC operon expression.

\section{Expression of the met/C operon is controlled by transcription antitermination}

In transcription antitermination systems, a transcriptional terminator forms in the leader region of the mRNA and determines whether transcription will terminate or continue. Northern blot experiments were performed to investigate the existence of a long metIC transcript and a short transcript. Total RNA was isolated from a culture of B. subtilis 168 grown in the presence of sulfate, or in the presence of sulfate plus methionine. Probes for the S-box and metI were used to detect specific metIC transcripts (Fig. 3). When sulfate was the sole sulfur source, a $2.5 \mathrm{~kb}$ transcript was detected by both probes (Fig. 3c, lanes 3 and 6). This transcript was not detected in RNA extracted from the $\Delta$ (S-box-metIC) mutant, BSIP1229 (Fig. 3c, lanes 1 and 4). It corresponds in length to a transcript initiated at the
metI promoter and terminated at the terminator located downstream of metC (Fig. 3a). In the presence of sulfate plus methionine, the amount of the $2.5 \mathrm{~kb}$ transcript decreased tenfold with the metl probe and eightfold with the S-box probe (Fig. 3c, lanes 2 and 5). These results are consistent with the regulation of the metIC operon in response to methionine availability observed with lac $Z$ transcriptional fusions. In addition to this full length mRNA, a $200 \mathrm{bp}$ transcript was specifically detected by the S-box probe. Its presence was detectable with the same intensity regardless of whether methionine was present or not (Fig. 3c, lanes 2 and 3). This transcript was not detected by the metI-specific probe or with RNA extracted from BSIP1229 [ $\Delta(\mathrm{S}$-box-metIC)] (Fig. 3c, lanes 1, 4, 5 and 6). A transcript of this size would be expected if RNA synthesis was initiated from the metI promoter and stopped at the terminator (helix 5 ) in the $3^{\prime}$-end of the S-box. The presence of the long and short transcripts correlates with a model of transcription antitermination.

\section{DISCUSSION}

The complete genome sequence of $B$. subtilis revealed three genes, yjcl, yjcJ and $y r h B$, encoding putative pyridoxal-dependent enzymes belonging to the cystathionine $\gamma$-synthase family (Cherest et al., 1993). We have shown that the YjcI (MetI) and YjcJ (MetC) proteins have central roles in methionine biosynthesis. In $B$. subtilis, homocysteine is synthesized by two metabolic pathways. The first one corresponds to the transsulfuration pathway present in enterobacteria, except that $\mathrm{O}$-acetylhomoserine is used as the substrate instead of O-succinylhomoserine (Kanzaki et al., 1986). Enzyme assays revealed that the MetI protein has cystathionine $\gamma$-synthase activity and could catalyse the synthesis of cystathionine from $\mathrm{O}$-acetylhomoserine and cysteine (Fig. 1). The complementation of the E. coli met $B$ mutant by the $B$. subtilis metI gene was probably due to marginal use of the $E$. coli substrate $O$ succinylhomoserine. The MetC protein has cystathionine $\beta$-lyase activity and catalyses the biosynthesis of homocysteine from cystathionine. Cystathionine appears to be an intermediate metabolite in the methionine biosynthesis pathway of B. subtilis. Disruption of the metC gene prevented B. subtilis from growing on cystathionine, as expected for a mutant inactivated in cystathionine $\beta$-lyase. Interestingly, the MetC protein is not essential for homocysteine synthesis in the presence of sulfate (Table 3), indicating that another pathway exists. YrhB, a MetI/MetC-like protein, which could be implicated in methionine degradation, is not involved.

The phenotype of the metI mutant (Table 3) shows that the MetI protein is important for the second pathway. The MetI polypeptide also exhibited O-acetylhomoserine thiolyase activity. This enzyme catalyses the synthesis of homocysteine from sulfide and $\mathrm{O}$ acetylhomoserine. Complementation with the metI gene allowed the B. subtilis $\Delta$ metIC mutant to grow with sulfate as its sole sulfur source. Therefore, the thiolation 
pathway (Fig. 1), which bypasses the formation of cystathionine, is functional in vivo in B. subtilis. The MetI protein has a dual cystathionine $\gamma$-synthase/Oacetylhomoserine thiolyase activity. O-Acetylhomoserine thiolyases from micro-organisms such as Corynebacterium acetophilum (Murooka et al., 1977), Leptospira meyeri (Belfaiza et al., 1998), Neurospora crassa (Kerr, 1971), Saccharomyces cerevisiae (Yamagata \& Takeshima, 1976) and Schizosaccharomyces pombe (Yamagata, 1984) do not catalyse the synthesis of cystathionine. It will be interesting to study the enzymic properties of MetI-like proteins in bacilli and other Gram-positive bacteria, since the purified Bacillus sphaericus cystathionine $\gamma$-synthase has $\mathrm{O}$ acetylhomoserine thiolyase activity in vitro (Kanzaki et al., 1987). In Pseudomonas aeruginosa and yeast, the thiolation pathway appears to be the major route for homocysteine synthesis, although the transsulfuration pathway also exists which implicates other genes. Whether the $\mathrm{O}$-acetylhomoserine thiolyase activity of MetI represents a major or an alternative pathway in $B$. subtilis remains to be clarified. In particular, the possible existence of regulatory mechanisms modulating the MetI activity deserves further investigations.

The MetI protein shares more similarities with the cystathionine $\gamma$-synthases of E. coli $(41 \cdot 8 \%$ identity) and Corynebacterium glutamicum ( $41 \cdot 1 \%$ similarity) than with the $\mathrm{O}$-acetylhomoserine thiolyases of Leptospira meyeri (28\% similarity) and Saccharomyces cerevisiae (29.7\% similarity). In addition, O-acetylhomoserine thiolyases contain a 30 aa insertion, in their central region, which is not present in the MetI sequence (Cherest et al., 1993). The hypothesis of Jensen (1976), concerning the molecular evolution of metabolic pathways, suggested that primitive enzymes have a very broad specificity and have further evolved to become more specific and efficient catalysts. While the MetI protein is more closely related to cystathionine $\gamma$ synthases, its binding site for thiol compounds is poorly specific because either cysteine or sulfide can be used as a sulfur donor. We propose that this protein has retained some of the ancestral properties of a primitive homocysteine synthase, the common ancestor of cystathionine $\gamma$-synthases and $O$-acetylhomoserine thiolyases (Cherest et al., 1993).

In $E$. coli, the met $C$ gene corresponds to a single transcriptional unit and the met $B$ gene forms an operon with metL, which encodes a bifunctional aspartokinase-homoserine dehydrogenase (Greene, 1996). In B. subtilis, the metI and metC genes, which probably correspond to the historically named met $A$ locus (Anagnostopoulos et al., 1993), are organized in an operon. A search of other sequences in the databases revealed a similar arrangement in Staphylococcus aureus, Clostridium acetobutylicum, Bacillus halodurans and Bacillus anthracis, indicating that this organization is conserved in a number of Gram-positive bacteria. An S-box motif is located upstream of the metIC-like operons in all of these organisms, except in Staphylococcus aureus.
Genes encoding amino acid biosynthesis enzymes in bacteria are generally expressed when the levels of the corresponding amino acid decrease. The metIC operon responds specifically to methionine availability and not to cysteine. Surprisingly, the expression of this operon is high in the presence of homocysteine, the methionine precursor (Fig. 1). Little is known about the regulation of expression of the other steps of the methionine biosynthetic pathway with the exception of the metK gene, which is two- to threefold regulated in response to exogenous methionine (Yocum et al., 1996). Further work is needed to estimate the metabolic fluxes and to study in more detail the different pathways connected to methionine biosynthesis.

The S-box has a key role in the control of transcription of the metIC operon, encoding two major steps of methionine biosynthesis. This motif is also found upstream of the genes encoding methionine synthase (metE) and $S$-adenosylmethionine synthase (metK), and is important for the regulation of the yitJ gene, which is thought to be involved in the synthesis of methionine (Grundy \& Henkin, 1998). In contrast, the regulation of expression of the $c y s H$ operon, which encodes the first steps of the cysteine biosynthesis, is independent of the S-box sequence located upstream of this operon (Mansilla et al., 2000). The S-box is not found in the upstream region of the other genes involved in cysteine biosynthesis. Therefore, the S-box system is probably devoted to the control of methionine metabolism, rather than to that of sulfur availability.

Analysis of the metIC operon revealed that its induction is independent of the promoter located upstream of the S-box sequence, but is dependent on the terminator of the leader region (Fig. 3, Table 5). We used Northern blot analysis to demonstrate that two transcripts exist: a small transcript corresponding to termination of transcription at the end of the S-box motif and a large one corresponding to transcription of the complete metIC operon. Therefore, the intrinsic terminator (helix 5 ) of the S-box motif is functional in B. subtilis. When methionine is limiting, the amount of full-length metIC transcript increases (Fig. 3c). This indicates that metIC expression is induced by partial alleviation of transcriptional termination at the S-box terminator in response to methionine availability. In contrast, the amount of the small transcript appears to be the same in the presence or absence of methionine. The secondary structure of the leader region could stabilize the small RNA. It is common for gene expression to be controlled at the level of transcription termination in prokaryotes (Henkin, 1996). In B. subtilis, the bgl-sac type of catabolic operons, the hut operon, the pyr and trp biosynthetic operons, the ssu (sulfonate-sulfur utilization) operon and the T-box controlled genes are all regulated by systems involving alternative RNA structures (Henkin, 1996; Oda et al., 2000; Rutberg, 1997; van der Ploeg et al., 2001). The critical differences between these systems are the molecules interacting with the leader region (tRNA or RNA-binding proteins) and how they modulate terminator and antiterminator 
formation. Further analyses are required to identify the regulatory factor(s) and the nature of the effector molecule involved in the control of the S-box regulon in response to methionine availability.

\section{ACKNOWLEDGEMENTS}

We thank Dr I. Saint-Girons, Dr A. Martel, M. F. Hullo and E. Turlin for helpful discussions. We are grateful to Dr H. Putzer and Dr I. Guillouard for helpful discussions and for critical reading of this manuscript.

This work was supported by research grants from the Centre National de la Recherche Scientifique, the Institut Pasteur, the University Paris 7 and the European Union Program (contract QLG2CT99011455).

\section{REFERENCES}

Alexander, F. W., Sandmeier, E., Mehta, P. K. \& Christen, P. (1994). Evolutionary relationships among pyridoxal-5'phosphate-dependent enzymes. Regio-specific alpha, beta and gamma families. Eur J Biochem 219, 953-960.

Anagnostopoulos, C., Piggot, P. J. \& Hoch, J. A. (1993). The genetic map of Bacillus subtilis. In Bacillus subtilis and Other Gram-positive Bacteria, pp. 425-461. Edited by A. L. Sonenshein, J. A. Hoch \& R. Losick. Washington, DC: American Society for Mircobiology.

Arantès, O. \& Lereclus, D. (1991). Construction of cloning vectors for Bacillus thuringiensis. Gene 108, 115-119.

Belfaiza, J., Parsot, C., Martel, A., de la Tour, C. B., Margarita, D., Cohen, G. N. \& Saint-Girons, I. (1986). Evolution in biosynthetic pathways: two enzymes catalyzing consecutive steps in methionine biosynthesis originate from a common ancestor and possess a similar regulatory region. Proc Natl Acad Sci US A 83, 867-871.

Belfaiza, J., Martel, A., Margarita, D. \& Saint-Girons, I. (1998). Direct thiolation for methionine biosynthesis in Leptospira meyeri. J Bacteriol 180, 250-255.

Bradford, M. M. (1976). A rapid and sensitive method for the quantitation of microgram quantities of protein utilizing the principle of protein-dye binding. Anal Biochem 72, 248-254.

Brush, A. \& Paulus, H. (1971). The enzymic formation of $O-$ acetylhomoserine in Bacillus subtilis and its regulation by methionine and $S$-adenosylmethionine. Biochem Biophys Res Commun 45, 735-741.

Calogero, S., Gardan, R., Glaser, P., Schweitzer, J., Rapoport, G. \& Débarbouillé, M. (1994). RocR, a novel regulatory protein controlling arginine utilization in Bacillus subtilis, belongs to the NtrC/NifA family of transcriptional activators. J Bacteriol 176, 1234-1241.

Cherest, H., Thomas, D. \& Surdin-Kerjan, Y. (1993). Cysteine biosynthesis in Saccharomyces cerevisiae occurs through the transsulfuration pathway which has been built up by enzyme recruitment. J Bacteriol 175, 5366-5374.

Danchin, A. (1989). Homeotopic transformation and the origin of translation. Prog Biophys Mol Biol 54, 81-86.

Duchange, N., Zakin, M. M., Ferrara, P., Saint-Girons, I., Park, I., Tran, S. V., Py, M. C. \& Cohen, G. N. (1983). Structure of the metJBLF cluster in Escherichia coli K12. Sequence of the metB structural gene and of the $5^{\prime}$ - and $3^{\prime}$-flanking regions of the metBL operon. J Biol Chem 258, 14868-14871.

Ferrari, F. A., Nguyen, A., Lang, D. \& Hoch, J. A. (1983).
Construction and properties of an integrable plasmid for Bacillus subtilis. J Bacteriol 154, 1513-1515.

Glatron, M.-F. \& Rapoport, G. (1972). Biosynthesis of the parasporal inclusion of Bacillus thuringiensis: half-life of its corresponding messenger RNA. Biochimie 54, 1291-1301.

Greene, R. C. (1996). Biosynthesis of methionine. In Escherichia coli and Salmonella: Cellular and Molecular Biology, 2nd edn, pp. 542-560. Edited by F. C. Neidhardt and others. Washington, DC: American Society for Microbiology.

Grundy, F. J. \& Henkin, T. M. (1998). The $S$ box regulon: a new global transcription termination control system for methionine and cysteine biosynthesis genes in Gram-positive bacteria. Mol Microbiol 30, 737-749.

Henkin, T. M. (1996). Control of transcription termination in prokaryotes. Annu Rev Genet 30, 35-57.

Jensen, R. A. (1976). Enzyme recruitment in evolution of new function. Annu Rev Microbiol 30, 409-425.

Jocelyn, P. C. (1987). Spectrophotometric assay of thiols. Methods Enzymol 143, 44-67.

Kanzaki, H., Kobayashi, M., Nagasawa, T. \& Yamada, H. (1986). Distribution of two kinds of cystathionine $\gamma$-synthase in various bacteria. FEMS Microbiol Lett 33, 65-68.

Kanzaki, H., Kobayashi, M., Nagasawa, T. \& Yamada, H. (1987). Purification and characterization of cystathionine $\gamma$-synthase type II from Bacillus sphaericus. Eur J Biochem 163, 105-112.

Kerr, D. S. (1971). O-Acetylhomoserine thiolase from Neurospora. Purification and consideration of its function in homocysteine and methionine synthesis. J Biol Chem 246, 95-102.

Kim, L., Mogk, A. \& Schumann, W. (1996). A xylose-inducible Bacillus subtilis integration vector and its application. Gene 181, 71-76.

Kredich, N. M. (1996). Biosynthesis of cysteine. In Escherichia coli and Salmonella: Cellular and Molecular Biology, 2nd edn, pp. 514-527. Edited by F. C. Neidhardt and others. Washington, DC: American Society for Microbiology.

Kunst, F. \& Rapoport, G. (1995). Salt stress is an environmental signal affecting degradative enzyme synthesis in Bacillus subtilis. J Bacteriol 177, 2403-2407.

Mansilla, M. C., Albanesi, D. \& de Mendoza, D. (2000). Transcriptional control of the sulfur-regulated $c y s H$ operon, containing genes involved in L-cysteine biosynthesis in Bacillus subtilis. J Bacteriol 182, 5885-5892.

Martel, A., Bouthier de la Tour, C. \& Le Goffic, F. (1987). Pyridoxal 5 -phosphate binding site of Escherichia coli $\beta$-cystathionase and cystathionine $\gamma$-synthase: comparison of their sequences. Biochem Biophys Res Commun 147, 565-571.

Miller, J. H. (1972). Experiments in Molecular Genetics. Cold Spring Harbor, NY: Cold Spring Harbor Laboratory.

Munier, H., Gilles, A. M., Glaser, P., Krin, E., Danchin, A., Sarfati, R. \& Barzu, O. (1991). Isolation and characterization of catalytic and calmodulin-binding domains of Bordetella pertussis adenylate cyclase. Eur J Biochem 196, 469-474.

Murooka, Y., Kakihara, K., Miwa, T., Seto, K. \& Harada, T. (1977). $\mathrm{O}$-Alkylhomoserine synthesis catalyzed by $\mathrm{O}$-acetylhomoserine thiolase in microorganisms. J Bacteriol 130, 62-73.

Murphy, E. (1985). Nucleotide sequence of a spectinomycin adenyltransferase $\mathrm{AAD}(9)$ determinant from Staphylococcus aureus and its relationship to $\operatorname{AAD}\left(3^{\prime \prime}\right)$ (9). Mol Gen Genet 200, 33-39.

Oda, M., Kobayashi, N., Ito, A., Kurusu, Y. \& Taira, K. (2000). cisActing regulatory sequences for antitermination in the transcript 
of the Bacillus subtilis hut operon and histidine-dependent binding of HutP to the transcript containing the regulatory sequences. Mol Microbiol 35, 1244-1254.

Ozaki, H. \& Shiio, I. (1982). Methionine biosynthesis in Brevibacterium flavum: properties and essential role of O-acetylhomoserine thiolase. J Biochem 91, 1163-1171.

Rutberg, B. (1997). Antitermination of transcription of catabolic operons. Mol Microbiol 23, 413-421.

Sambrook, J., Fritsch, E. F. \& Maniatis, T. (1989). Molecular Cloning: a Laboratory Manual, 2nd edn. Cold Spring Harbor, NY: Cold Spring Harbor Laboratory.

Sanger, F., Nicklen, S. \& Coulson, A. R. (1977). DNA sequencing with chain-terminating inhibitors. Proc Natl Acad Sci US A 74, 5463-5467.

Sekowska, A., Kung, H. F. \& Danchin, A. (2000). Sulfur metabolism in Escherichia coli and related bacteria: facts and fiction. J Mol Microbiol Biotechnol 2, 145-177.

Stülke, J., Martin-Verstraete, I., Zagorec, M., Rose, M., Klier, A. \& Rapoport, G. (1997). Induction of the Bacillus subtilis ptsGHI operon by glucose is controlled by a novel antiterminator, GlcT. Mol Microbiol 25, 65-78.

Tabor, S. \& Richardson, C. C. (1985). A bacteriophage T7 RNA polymerase/promoter system for controlled exclusive expression of specific genes. Proc Natl Acad Sci U S A 82, 1074-1078.

Thomas, D. \& Surdin-Kerjan, Y. (1997). Metabolism of sulfur amino acids in Saccharomyces cerevisiae. Microbiol Mol Biol Rev 61, 503-532.

Trieu-Cuot, P. \& Courvalin, P. (1983). Nucleotide sequence of the Streptococcus faecalis plasmid gene encoding the $3^{\prime} 5^{\prime \prime}$-aminoglycoside phosphotransferase type III. Gene 23, 331-341.
Uren, J. R. (1987). Cystathionine $\beta$-lyase from Escherichia coli. Methods Enzymol 143, 483-486.

Van der Ploeg, J. R., Barone, M. \& Leisinger, T. (2001). Expression of the Bacillus subtilis sulphonate-sulphur utilization genes is regulated at the levels of transcription initiation and termination. Mol Microbiol 39, 1356-1365.

Wach, A. (1996). PCR-synthesis of marker cassettes with long flanking homology regions for gene disruptions in $S$. cerevisiae. Yeast 12, 259-265.

Weissbach, H. \& Brot, N. (1991). Regulation of methionine synthesis in Escherichia coli. Mol Microbiol 5, 1593-1597.

Yamagata, S. (1984). O-Acetylhomoserine thiolase of the fission yeast Schizosaccharomyces pombe: partial purification, characterization, and its probable role in homocysteine biosynthesis. $J$ Biochem 96, 1511-1523.

Yamagata, S. (1987). O-Acetyl-L-serine-O-acetyl-L-homoserine thiolase from Saccharomyces cerevisiae. Methods Enzymol 143, 478-483.

Yamagata, S. (1989). Roles of O-acetyl-L-homoserine thiolases in micro-organisms. Biochimie 71, 1125-1143.

Yamagata, S. \& Takeshima, K. (1976). O-Acetylserine and Oacetylhomoserine thiolase of yeast. Further purification and characterization as a pyridoxal enzyme. J Biochem 80, 777-785.

Yocum, R. R., Perkins, J. B., Howitt, C. L. \& Pero, J. (1996). Cloning and characterization of the metE gene encoding $S$-adenosylmethionine synthetase from Bacillus subtilis. J Bacteriol 178, 4604-4610.

Received 27 June 2001; revised 15 August 2001; accepted 1 October 2001. 